
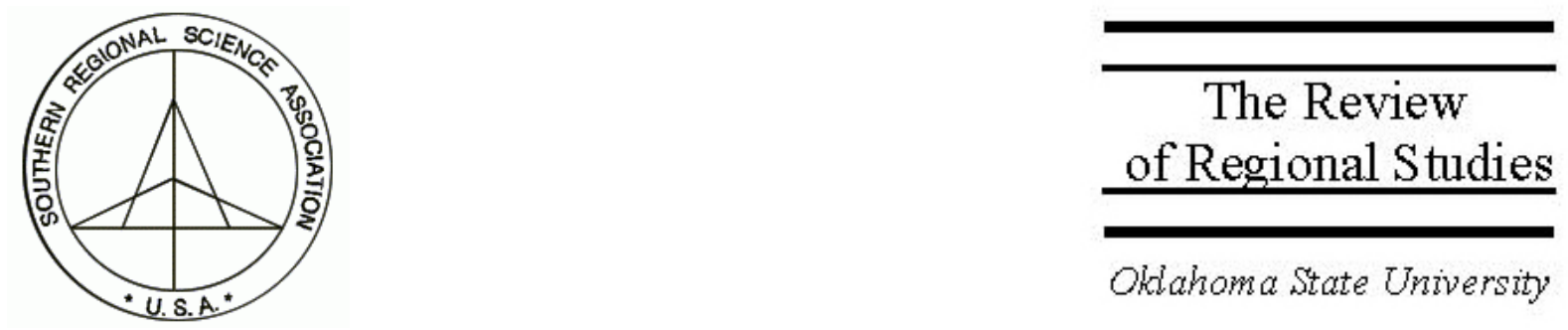

\title{
Decomposition of Regional Income Inequality in Korea
}

\author{
Euijune Kim \\ Department of Urban Planning and Engineering, Yonsei University, 134 Shinchon-Dong, \\ Seodaemun-Gu, Seoul 120-749, Korea and Regional Economics Applications Laboratory, \\ University of Illinois, Urbana, Illinois, email: ejkim@yonsei.ac.kr \\ Youn Hee Jeong \\ Urban and Regional Planning Research Division, Korea Research Institute for Human Settlements \\ Kyunggi-do, Korea
}

\begin{abstract}
This paper analyzes sources of income inequality in Korea with respect to income source and region. When the Gini index of overall income inequality was decomposed by geographical boundaries, the relative contribution of between-region inequality to the total was 67.96 percent in 1995, showing a Gini index of 0.315. Half of this income inequality (a Gini index of 0.234) was attributable to the difference in incomes between the Seoul Metropolitan Area and the rest of the nation, and two-thirds of the income inequality within regions (a Gini index of 0.101) was attributable to the level of income inequality between subregions of the Seoul Metropolitan Area.
\end{abstract}




\section{INTRODUCTION}

Regional disparity in Korea has showed a trend of convergence, diminishing and stabilizing in the range of 0.076-0.090 for the Gini coefficient of regional per capita income after a dramatic drop in 1986 (Kim, Hong, and Ha 2003). Most Korean studies agreed that the inequality reached its peak and then revealed a steady decrease following Williamson's (1965) inverted-U hypothesis (Mera 1973, Rao 1978, Hwang 1982, Hur 1989, Hong 1990, Yoo 1991, and Byun 1997). However, the government has still placed a top priority on alleviating regional inequality in spite of the exceptional success in achieving both rapid economic growth and wide distribution of incomes as pointed out by Rao (1978).

There are two main regional problems in Korea: an over-concentration of economic activities and population in the Seoul Metropolitan Area, including Seoul and its adjacent provinces, and hostile regionalism. In continuing attempts to solve the former, the government has employed several decentralization measures: development of local industrial complexes outside the Seoul Metropolitan Area, establishment of greenbelts, implementation of a residence tax, and relocation of secondary administration offices. Various degrees of restriction on land use have been put in place to allow stringent control of population density in the Seoul Metropolitan Area. A development charge has been imposed on the construction of population-inducing facilities. In addition, exemptions from corporate taxes and the provision of matching funds are offered to large corporations that relocate away from the Seoul Metropolitan Area to the rest of the nation. However, the population share of the Seoul Metropolitan Area grew from 39.1 in 1985 to 46.5 percent in 2000. During the same period, its regional share of employment and income also increased by 13.0 and 5.7 percentage points, respectively.

On the other hand, the regionalism of Korea did not originate from social cleavage, unlike other countries (Mah 2002). ${ }^{1}$ The most serious regional conflict has occurred between the Southeast and Southwest Areas since 1970s. The regional-based political party received exclusive and monopolistic electoral supports from hometown voters with few cross-votes from the competing region. Every candidate from the Southeast Area won during presidential campaigns until the late 1990s simply due to a larger population size than the Southwest Area. The Southeast Area succeeded in hosting seven of the nine national industrial complexes (base) in the 1980s.

In order to solve regional inequality problems, it is necessary to identify the region's contribution to the inequality. The purpose of this paper is to analyze the sources of regional disparity in Korea by decomposing the overall income inequality into between-region and within-region inequalities. Income is divided into wages and salaries, business income, asset income, subsidies, and other income. Korea was disaggregated into four regions, i.e., the Seoul Metropolitan Area, the Central Area, the Southeast Area, and the Southwest Area. Each region is composed of a few subregional units (discussed in Section 4). The paper is organized in the following way. Section 2 reviews the previous research on the decomposition of income inequality and the development of the decomposition methodology, and Section 3 calibrates the contribution of each income source and region to the overall income inequality. Finally,

\footnotetext{
${ }^{1}$ In general, regional conflicts are attributable to real cleavage factors such as class in Italy, religion and race in North Island, and language and culture in Canada; but there are no such substantive issues in Korea (Mah 2002).
} 
Section 4 presents conclusions and policy implications based on the foregoing analyses.

\section{METHOD}

\subsection{Literature Review}

In terms of the decomposability of income inequality measures, Bourguignon (1979) argued that the Theil index and the logarithm of the arithmetic mean over the geometric mean were the only decomposable inequality measures, such that the weight of within-region components in the total inequality of a partitioned population summed to a constant. Foster, Greer, and Thorbecke (1984) developed the Foster-Greer-Thorbecke class of poverty measures that could be additively decomposable using population-share weights. Dagum (1997) succeeded in proving that the Gini index could be also additively decomposed into the weighted sum of components, the Gini inequality within subpopulations, and the Gini inequality between subpopulations. Costa and Michelini (1999) showed that decomposition of the Gini index could be calibrated to the contribution of subpopulations to total inequality more accurately than could the Theil index.

With respect to decomposing the overall income inequality into contributions by income source in 1990s, Adams and Alderman (1992) showed that the distribution of agricultural income in rural Pakistan had major impacts on total rural income. ${ }^{2}$ Wage and crop profits significantly affected inequality in agricultural income, but the ownership of land was not the main source of inequality. They suggested that technical assistance such as offering managerial and technical skills to agriculturists could result in a more equitable rural income distribution and that more attention should be paid to livestock production because of its positive impact on income equity. Adams (1999) showed that a 1 percent increase in nonfarm income in rural Egypt reduced the Gini index of overall income by 12.8 percent, whereas 1 percent growth in agricultural income increased the inequality by 15.8 percent. Consequently, it recommended that policymakers focus on nonfarm income, which not only accounted for almost 60 percent of the total income for the rural poor but also favorably affected income distribution. Milanovic (1999) argued that the Gini index for world incomes increased from an already very high level of 0.63 in 1988 to 0.66 in 1993 because of greater differences in incomes between countries than within countries. In China the determinant of income distribution was an urban-rural difference, whereas in South Asian countries it was slow growth in rural purchasing-power adjusted income compared to developed countries. Glewwe, Gragnolati, and Zaman (2000) examined factors that contributed to poverty reduction in Vietnam by using both a decomposition analysis and a multinomial logit model based on two household surveys, one for 1992-1993 and the other for 1997-1998. They showed that returns to education increased significantly, particularly for higher levels of education, and that the location of a household affected its probability of escaping poverty. Urban households enjoyed a greater reduction in poverty than rural households. Yemtsov (2001) found that former Soviet Georgia reached the highest level of income inequality with a Gini index of 0.6 and that informal incomes had the greatest impact on changing the income inequality. Marcelin and Edgard (2001) examined the evolution of inequality among family

\footnotetext{
${ }^{2}$ One of the pioneer works is Shorrocks (1982). It analyzed the impact of income components on the distribution of family incomes in the United States, evaluating the performance of different decomposition approaches. Shorrocks (1984) also assessed the contribution of various income sources such as earnings, investment income, and transfer payments to the total income inequality of individuals and households.
} 
incomes in Canada during the period from 1986 to 1996 by decomposing entropy indices and the Gini index. Family composition characteristics rather than population aging or location considerably influenced both the level of income inequality and the growth rate of inequality. They suggested that the policy of redistribution of incomes was successful in eliminating the inequality between groups that had arisen from different family composition characteristics and concluded that taxation and transfer systems were jointly responsible for the stable level of disposable income inequality between 1986 and 1996. Milanovic and Yitzhaki (2001) found that Asia was regarded as the most heterogeneous continent in the sense that between-country inequality was more important than within-country inequality. On the contrary, Africa, Latin America, and Western Europe/North America were quite homogeneous continents with small differences in incomes.

Whereas most Korean studies, including those of Choo (1979), Kwon et al. (1992), and Lee (1997), focused on changes in the overall inequality index, there have been a few studies to analyze income inequality in terms of either the source of income or the population group. One of them is Rho and Bae (1998), which estimated the contributions of various income sources to the total income inequality by decomposing the Gini income inequality index. They found that business income and wages and salaries accounted for 63.8 percent and 26.4 percent, respectively, of overall income inequality but that the contribution of asset income to income inequality was insignificant. Jeong and Choi (2001) also decomposed income inequality by population group. Their research revealed that the degree of income inequality depended heavily on the distribution of wages and salaries following the financial crisis of 1997.

To date, only a limited number of studies have decomposed income inequality by geographical region (Johnston, McKinney, and Stark 1996 for the United Kingdom; Terrasi 1999 for Italy; Azzoni 2001 for Brazil; and Fujita and Hu 2001 for China). Johnston, McKinney, and Starke (1996) argued that both between-region and within-region inequality increased from 1979 to 1993 in the United Kingdom, but that the level and growth rate of interregional income inequality were smaller than those within-regions. The relative share of between-region income inequality to the total was increased to more than double, from 2.4 in 1979-1980 to 6.2 percent in 1990-1991, in terms of the Theil index. An increase from 15.0 to 21.6 percent was shown during the same period with respect to the Gini index. Terrasi (1999) found a tendency toward convergence in the Theil index from 1960 to 1975; however, after 1975 the trends in income inequality depended on the cycles of expansion and recession of the national economy. The relative share of interregional income disparity to the total between northern and southern Italy rose from 62.8 in 1953 to 90.0 percent in 1983 and fluctuated between 89.8 percent in 1989 and 91.8 percent in 1993. Fujita and $\mathrm{Hu}(2001)$ identified an increase in income disparity between the coastal and the interior areas of China, from 0.010 in 1984 to 0.026 in 1995 in terms of the Theil index. The share of inequality between these regions rose from 22.6 to 56.8 percent during the same period. Industrial production showed a strong agglomeration toward the coastal areas, and a trend of convergence was also observed in these areas. These data imply that globalization and economic liberalization resulted in an increase in regional disparity. Azzoni (2001) tested the Kuznetz hypothesis of regional income inequality in Brazil. A convergence in regional income was found from a regression analysis as well as oscillations in the evolution of inequality over time and across regions within the country. The share of betweenregion inequality to the total decreased from 77.1 in 1980 to 73.5 percent in 1988 , and then a 
long-term increasing tendency in the share of inequality appeared until 1995 (80.24 percent).

\subsection{Methodology}

There is no rule for choosing an appropriate income inequality index, and the ranking of measures is not feasible since each of these measures satisfies some desirable properties (Zandvakili and Mills 2001). Two indices, the Theil index and the Gini index, are often used to measure the extent to which inequality in the total population is attributable to inequalities within and between groups. The Theil index has been known as the only member of the generalized entropy class of inequality measures to satisfy additive decomposability until the late 1990s. However, if the income distributions vary substantially across the groups or the average incomes of the groups are smaller than the population average, the Theil index for the between-groups inequality could be negative (Costa and Michelini 1999). ${ }^{3}$ For example, the contribution of the poorest region to the Theil index of southern Italy was negative. In the late 1990s, the Gini index was also revealed to be additively decomposable (Dagum 1997). In particular, the Gini index depends on neither the number of regions nor on extreme values, taking into account the differences between the incomes of all binary combinations of all income earners in contrast to the case of the Theil index (Costa and Michelini 1999). Thus, this paper uses the Gini index for estimating the contribution of various income sources and regions to the overall income inequality.

The Gini index $(G)$ for a regional analysis is shown in Equation (1). According to Dagum (1997), the index is decomposed into the Gini index within region $j$ in Equation (2) and between regions in Equation (3) for a nation composed of $k$ regions with a regional population of size $n_{j}$. If the relative size of region $j$ and the share of regional income are defined as $P_{j}$ and $S_{j}$, respectively, the Gini index for total inequality can be written as Equation (4). The inequality within regions is derived from Equation (5) as a weighted average of the regions' Gini index, and the inequality between regions is derived from Equation (6).

(1) $G=\frac{1}{2 n^{2} \mu} \sum_{j=1}^{k} \sum_{h=1}^{k} \sum_{i=1}^{n_{j}} \sum_{r=1}^{n_{h}}\left|y_{j i}-y_{h r}\right|$

(2) $G_{j j}=\frac{1}{2 n_{j}^{2} \mu_{j}} \sum_{i=1}^{n_{j}} \sum_{r=1}^{n_{j}}\left|y_{j i}-y_{h r}\right|$

(3) $G_{j h}=\frac{1}{n_{j} n_{h}\left(\mu_{j}+\mu_{h}\right)} \sum_{i=1}^{n_{j}} \sum_{r=1}^{n_{h}}\left|y_{j i}-y_{h r}\right|$

(4) $G=\sum_{j=1}^{k} \sum_{h=1}^{k} G_{j h} p_{j} S_{h}$

\footnotetext{
3 Theil index is determined only by the average incomes of the groups without distributional characteristics of incomes. Thus, the share of income inequality among the four macro regions in Korea to the total inequality remains only 2.03 percent.
} 
(5) $G_{w}=\sum_{j=1}^{k} G_{i j} p_{j} S_{j}$

(6) $G_{b}=\sum_{j=1}^{k} \sum_{h=1}^{k} G_{j h} p_{j} S_{h}$

$G$ : Gini index

$G_{j j}$ : Gini index within region $j$

$G_{j h}$ : Gini index between regions $j$ and $h$

$G_{w}:$ Gini index within-regions

$G_{b}$ : Gini index between-regions

$\mu_{j}$ : the mean of the $j$ th subpopulation

$n_{j}$ : population size of group $j$

$p_{j}:$ the relative size of region $j$

$s_{j}$ : the regional income share

To decompose the Gini index of total income inequality by income source, such as by wages or asset income, $Y_{j i}$ is redefined as the value of income source $i$ for individual $j$ (Silber 1989). $Y_{. i}$ from Equation (7) and $Y_{j}$. from Equation (8) are total incomes of income source $i$ and of individual $j$, respectively. $Y$ represents the total incomes of the population, and $\mathrm{S}_{. i}$ and $S_{j}$ imply the weight of income source $i$ and the share of individual $j$ of total income, respectively.

(7) $Y_{. i}=\sum_{j=1}^{n} Y_{j i}$

(8) $Y_{j .}=\sum_{i=1}^{I} Y_{j i}$

(9) $S_{j i}=\frac{Y_{j i}}{Y}$

(10) $S_{. i}=\frac{Y_{. i}}{Y}$

(11) $S_{j .}=\frac{Y_{j}}{Y}$ 
Silber (1989) defined the Gini index, $I_{G}$, of overall income inequality as shown in Equation (12), where $\left[e^{\prime}\right]$ is a $1 \times n$ row vector of population shares, each equal to $(1 / n)$; and $[S]$ is the $n \times 1$ column vector of the income shares $S_{j} . \quad G$ is an $n \times n$ square matrix whose typical element $g_{h k}$ is equal to 0 if $h=k$, to -1 if $h<k$, and to +1 if $h>k$. The terms $\left[S_{j i}\right]$ on the right-hand side of the $G$-matrix are column vectors whose typical elements are equal to $S_{j i}$. The Gini index is defined as in Equation (13), where $V_{j i}$ represents the share $\left(\mathrm{Y}_{j i} / \mathrm{Y}_{i}\right)$ of individual $j$ in income source $i . \quad H_{i}$ and $C_{i}$ are the pseudo-Gini index and the contribution of income source $i$ to the overall inequality, respectively, where $\left[V_{j i}\right]$ represents the $n \times 1$ vector of the shares $V_{j i}{ }^{4}$

$$
\begin{aligned}
I_{G} & =\left[e^{\prime}\right] G[S] \\
I_{G} & =\left[e^{\prime}\right] G\left[\sum_{i=1}^{I} S_{. i}\left[V_{j i}\right]\right] \\
& =\sum_{i} S_{i} H_{i} \\
& =\sum_{i} C_{i}
\end{aligned}
$$

\section{ANALYSIS}

We use the Korean Household Panel Study (KHPS) of 1995 by the Daewoo Economic Research Institute (1996) for the analysis of income inequality. The panel survey has been carried out continuously every year since 1993 with approximately 4,500 Korean households. It is the first systematic and multi-year longitudinal data set ever compiled on incomes and expenditures of a representative sample of individuals and family units in Korea. This basic structure for the KHPS survey process is similar to the Panel Study of Income Dynamics (PSID) by the University of Michigan (2003), one of the most important and widely cited surveys in the social sciences of the U.S. The KHPS provides a wide variety of information such as income and wealth, expenditures, employment, family composition, housing, and residential and employment locations. The contents on socioeconomic and demographic variables have remained largely unchanged in order to maintain the comparability of the data over long periods. The samples are collected with face-to-face interviews with the original households interviewed in 1993 as well as new households split off from their families. This implies that each wave of the KHPS includes dependent information on the associated individuals and derivative households for the original households of 1993. Multistratified random sampling has been applied in a geographic clustering design such as the primary sampling unit (city and province unit), the secondary sampling unit (neighborhood unit), and the third sampling unit (block and street unit). The total number of the responding households is 3,108 , which seems to be small. On the other hand, the sample size per region of the KHPS in 1995 is roughly 1.7 times as large as that of the U.S. PSID. in 2001, and the samples have been systematically selected as discussed above. Thus the sample sizes are not deficient for the statistical analysis.

\footnotetext{
${ }^{4}$ Because $V_{j i}$ may not decrease monotonically, $H_{i}=\left[e^{\prime}\right] \mathrm{G}\left[V_{\mathrm{ji}}\right]$ is called the pseudo-Gini of income source $i$.
} 
In the KHPS, total income is composed of five income sources: wages and salaries; business income; asset income, including interest, rent, and other asset income; income from public transfers, including welfare and relief payments, subsidies, pensions, remittances from the government, rewards, compensations, and other transfers; and other income sources. The country was classified into the following four regions (Figure 1): the Seoul Metropolitan Area (Seoul, Incheon, and Kyungki), the Central Area (Kangwon, Daejon, Chungbuk, and Chungnam), the Southeast Area (Busan, Daegu, Kyungbuk, and Kyungnam), and the Southwest Area (Kwangju, Jeonbuk, and Jeonnam).

Since households differ in size and composition, it is necessary to employ the concept of adjusted income in analyzing income distribution. ${ }^{5}$ A deflated household income was used as the income unit in order to eliminate the composition effects from differences in the number of household members. That is, an appropriate equivalence scale $(E)$ deflates the household income to take household size effect into account, as shown in Equation (14). The equivalence elasticity ranges from 0 to 1 . If $E$ is 0 , no adjustment could be made; on the contrary, if $E$ is 1 , household income could become per capita income. The scale values greatly vary in the emphasis of increments to family size, so there is no solid agreement on the definition of the value. According to the Luxembourg Income Study of OECD by Atkinson, Rainwater, and Smeedling (1995), the median values were 0.59 for the study of social programs and 0.57 for that of consumer expenditures. In the sense that the overall average of scales for 54 cases of OECD

\section{FIGURE 1}

\section{Regional Classification of Korea}

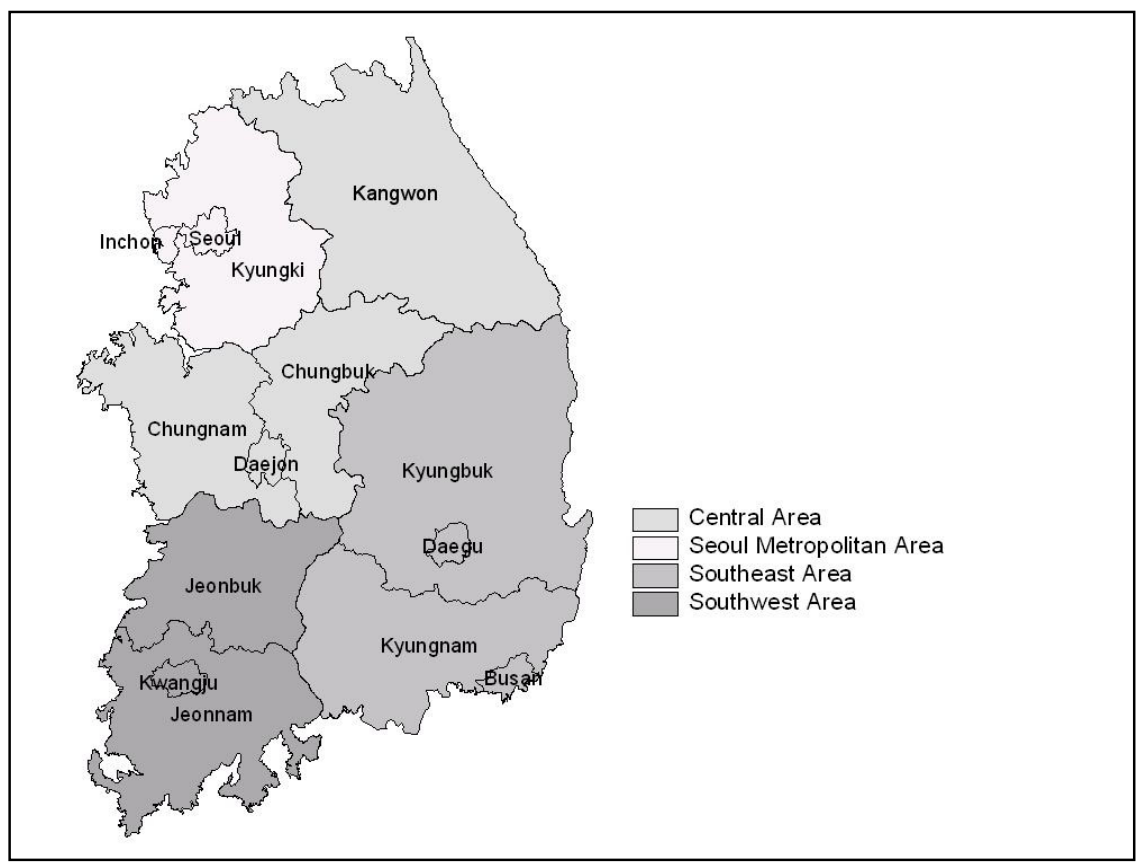

\footnotetext{
${ }^{5}$ Families with multiple members may enjoy substantial economies of scale in their living expenditures. If household income is considered as the imputation unit, the smaller households enjoy a higher real income than the larger ones under an equal nominal income.
} 
countries is 0.54 and those of Atkinson, Rainwater, and Smeedling (1995) and Hyun and Kang (1998) are 0.50, this study sets the value of the parameter at 0.5, assuming a moderate level of economies of scale.

(14) Adjusted Income $=\frac{\text { Income }}{(\text { household size })^{\mathrm{E}}}$

Table 1 shows average regional income and sample size by region. The regional shares of the samples from KHPS are not very different from those of population in 1995 in the sense that differences between the sample and the population range from 0.1 in Kwangju to 3.4 percentage points in Seoul and Kyungki. The average total income in the Seoul Metropolitan Area was higher than the national average by U.S. \$4,550, whereas the total income level in the Southwest Area remained the lowest. Among the six largest cities with populations exceeding one million, only Incheon had an income lower than the income average shown in each macro region. Also, two provinces were higher than the national average: Kyungki in the Seoul Metropolitan Area and Kangwon in the Central Area. The Seoul Metropolitan Area was the most developed region and had the highest income level, whereas the Southeast Area had a higher income average than the Southwest region by U.S. \$2,343. The average income of Incheon is higher but more volatile (as measured by the standard deviation) than that of the nation.

\section{TABLE 1}

Sample Distribution and Average Income of Households by Region (\$U.S.)

\begin{tabular}{|c|c|c|c|c|c|c|}
\hline \multirow[b]{2}{*}{ Seoul } & \multicolumn{2}{|c|}{ Sample of KHPS } & \multicolumn{2}{|c|}{ Population } & \multirow{2}{*}{$\frac{\text { Average Income }}{23,827}$} & \multirow{2}{*}{$\frac{\text { Standard Deviation }}{10,515}$} \\
\hline & 826 & $(26.6)$ & $2,965,794$ & $(23.2)$ & & \\
\hline Incheon & 142 & (4.6) & 658,818 & (5.1) & 16,914 & 6,946 \\
\hline Kyungki & 420 & $(13.5)$ & $2,168,007$ & $(16.9)$ & 20,967 & 9,199 \\
\hline Daejon & 82 & $(2.6)$ & 357,814 & $(2.8)$ & 18,822 & 10,260 \\
\hline Kangwon & 94 & $(3.0)$ & 440,955 & (3.4) & 20,468 & 12,019 \\
\hline Chungbuk & 120 & (3.9) & 407,664 & (3.2) & 17,457 & 9,069 \\
\hline Chungnam & 149 & $(4.8)$ & 514,254 & $(4.0)$ & 16,675 & 8,810 \\
\hline Busan & 274 & $(8.8)$ & $1,079,417$ & (8.4) & 19,795 & 9,136 \\
\hline Daegu & 149 & (4.8) & 703,464 & (5.5) & 18,938 & 7,867 \\
\hline Kyungbuk & 221 & (7.1) & 824,891 & (6.4) & 14,178 & 8,484 \\
\hline Kyungnam & 237 & (7.6) & $1,141,523$ & (8.9) & 15,615 & 8,188 \\
\hline Kwangju & 89 & (2.9) & 354,717 & $(2.8)$ & 14,966 & 7,264 \\
\hline Jeonbuk & 129 & $(4.2)$ & 556,985 & $(4.4)$ & 14,815 & 8,903 \\
\hline Jeonnam & 176 & $(5.7)$ & 637,452 & $(5.0)$ & 14,662 & 7,188 \\
\hline Total & 3,108 & $(100.0)$ & $12,811,755$ & $(100.0)$ & & \\
\hline
\end{tabular}


TABLE 2

Decomposition of the Gini Index by Income Source

\begin{tabular}{llllllll}
\hline \multicolumn{1}{c}{ Gini Index (\%t) } & \multicolumn{2}{c}{ Total } & \multicolumn{2}{c}{ Within Regions } & \multicolumn{2}{c}{ Between Regions } \\
\hline Wages and salaries & 0.337 & $(100)$ & 0.117 & $(34.78)$ & 0.220 & $(65.22)$ \\
Business income & 0.430 & $(100)$ & 0.119 & $(27.67)$ & 0.311 & $(72.33)$ \\
Asset income & 0.700 & $(100)$ & 0.215 & $(30.73)$ & 0.485 & $(69.27)$ \\
Subsidies & 0.498 & $(100)$ & 0.135 & $(27.20)$ & 0.362 & $(72.80)$ \\
Other income & 0.869 & $(100)$ & 0.279 & $(32.08)$ & 0.590 & $(67.92)$ \\
\hline Total income & 0.464 & $(100)$ & 0.149 & $(32.04)$ & 0.315 & $(67.96)$ \\
\hline
\end{tabular}

Table 2 shows that the Gini index for total income is 0.464 and that the relative contribution of between-region inequality to total inequality is 67.96 percent (a Gini index of 0.315 ). The distribution of asset income shows more bias toward high-income groups than any other income source; however, wages and salaries are the most equally distributed across the income groups. The relative share of between-region inequality for business income is higher than that of two other income sources by 3.06 (asset income) and by 7.11 percentage points (wages and salaries), although its Gini index is lower than that of asset income by 0.174 . This result implies that traditional spatial relocation policy instruments of labor such as generating employment opportunities in less-developed regions in Korea could not have a substantial effect on the reduction of income disparity, since the contribution of wages and salaries to the income inequality by region and for the nation remained at only 15.1 to 22.8 percent. $^{6}$

As shown in Table 3, the Gini index of 0.149 within regions (relative contribution, 32.04 percent) had four components: 0.101 for the Seoul Metropolitan Area, 0.032 for the Southwest Area, 0.009 for the Central Area, and 0.007 for the Southeast Area. About one-quarter of the income inequality between regions was attributable to the difference in incomes between the Seoul Metropolitan Area (the highest income region) and the Southeast Area (the lowest income region). Interregional inequality between the Seoul Metropolitan Area and the Central Area also accounted for 13.64 percent of the total. Unexpectedly, the share of interregional inequality between the Southeast and Southwest Areas registered only 6.36 percent, the second lowest among the six cases. In fact, the Southeast Area was recognized to be much more developed than the Southwest Area as discussed in Section 1. As a whole, these results reconfirm that the interregional disparity between the Seoul Metropolitan Area and the rest of Korea is the primary source of regional inequality in Korea. In addition, government efforts need to be made toward reducing intraregional inequality in the Seoul Metropolitan Area as much as in regional income inequality, as its contribution to income inequality was 21.73 percent, not a negligible level.

The income inequality for each region can be decomposed into between-subregion and within-subregion components or income source components. As can be seen in Table 4, the income inequality between subregions was consistently a significant source of income disparity

\footnotetext{
${ }^{6}$ For Korea, the traditional labor policy instruments designed to stimulate balanced regional development have included occupational and educational training and subsidies for housing costs to migrants, whereas the capital instruments include tax relief and holidays, relaxation of land use regulations, and capital grants and interest relief.
} 
TABLE 3

Decomposition of Total Income Inequality by Region

\begin{tabular}{lrr}
\hline & Gini Index & $(\%)$ \\
\hline Total income & 0.464 & $(100.00)$ \\
Within regions & 0.149 & $(32.04)$ \\
Seoul Metropolitan Area & 0.101 & $(21.73)$ \\
Southwest Area & 0.032 & $(6.83)$ \\
Central Area & 0.009 & $(2.05)$ \\
Southeast Area & 0.007 & $(1.42)$ \\
Between regions & 0.315 & $(67.96)$ \\
Seoul Metropolitan Area-Central Area & 0.063 & $(13.64)$ \\
Seoul Metropolitan Area-Southwest Area & 0.116 & $(25.02)$ \\
Seoul Metropolitan Area-Southeast Area & 0.055 & $(11.95)$ \\
Central Area-Southwest Area & 0.035 & $(7.52)$ \\
Southwest Area-Southeast Area & 0.029 & $(6.36)$ \\
\hline Central Area-Southeast Area & 0.016 & $(3.47)$ \\
\hline
\end{tabular}

for all four regions. The share of wages and salaries to the total income inequality was higher than that of business income and asset income for all regions except the Southeast Area. For the Seoul Metropolitan Area, income inequality between subregions constituted 51.84 percent of the total income inequality, whereas the shares for asset income and wages and salaries remained at 50.90 and 52.96 percent, respectively. These levels were much lower than any others in three regions by at least 7.34 (business income of the Southwest Area) to 24.55 percentage points (business income of the Southeast Area), implying that the Seoul Metropolitan Area could be regarded as a relatively homogeneous economic space compared with other areas. In contrast, the income distribution of the Central and Southeast Areas was related more to income inequality between subregions.

When the Gini index of overall total income was decomposed into the various income sources, the ratio of asset income to total income inequality was as high as 46.0 percent for the nation and 41.2 (Southeast Area) to 50.6 percent (Seoul Metropolitan Area and Southwest Area) for the regional levels (Table 5). The inequalities for wages and salaries and for business income could account for about 20.2 percent and 24.0 percent of the overall income inequality, respectively; whereas for the Southwest Area the wage and salary component had a greater effect than the business income component on income distribution.

\section{TABLE 4}

Relative Contribution of Inequality Between Subregions to the Total (\%)

\begin{tabular}{lcccccc}
\hline & $\begin{array}{c}\text { Total } \\
\text { Income }\end{array}$ & $\begin{array}{c}\text { Wages and } \\
\text { Salaries }\end{array}$ & $\begin{array}{c}\text { Business } \\
\text { Income }\end{array}$ & $\begin{array}{c}\text { Asset } \\
\text { Income }\end{array}$ & Subsidies & Other \\
\hline Seoul Metropolitan Area & 51.84 & 52.96 & 51.51 & 50.90 & 51.3 & 52.3 \\
Central Area & 73.65 & 75.08 & 72.02 & 74.23 & 76.7 & 74.0 \\
Southwest Area & 64.16 & 67.06 & 58.85 & 63.03 & 66.0 & 68.5 \\
Southeast Area & 74.12 & 73.91 & 75.06 & 74.10 & 74.7 & 74.0 \\
\hline
\end{tabular}


TABLE 5

Relative Contribution of Each Income Source to the Total Income Inequality (\%)

\begin{tabular}{lccccc}
\hline & $\begin{array}{c}\text { Wages and } \\
\text { Salaries }\end{array}$ & $\begin{array}{c}\text { Business } \\
\text { Income }\end{array}$ & $\begin{array}{c}\text { Asset } \\
\text { Income }\end{array}$ & Subsidies & Other \\
\hline Nation & 20.2 & 24.0 & 46.0 & 0.2 & 9.7 \\
Seoul Metropolitan Area & 15.1 & 24.9 & 50.6 & 0.0 & 9.4 \\
Central Area & 21.6 & 22.6 & 41.5 & 0.0 & 14.3 \\
Southeast Area & 22.9 & 25.4 & 41.2 & 0.2 & 10.3 \\
Southwest Area & 22.8 & 19.9 & 50.6 & 0.9 & 5.7 \\
\hline
\end{tabular}

TABLE 6

Changes in the Gini Index for Income Subsidies

\begin{tabular}{lcccccc}
\hline Gini Index (\%) & \multicolumn{2}{c}{ Total } & \multicolumn{2}{c}{ Within Region } & \multicolumn{2}{c}{ Between Region } \\
\hline Pre-transfer payment & 0.466 & $(100)$ & 0.134 & $(28.72)$ & 0.332 & $(71.28)$ \\
Post-transfer payment & 0.464 & $(100)$ & 0.130 & $(28.02)$ & 0.334 & $(71.98)$ \\
\hline
\end{tabular}

As shown in Table 6, income subsidies succeeded in reducing the Gini index, although the contribution of subsidies to the total income inequality was less than 1 percent. Surprisingly, however, it had an adverse effect on regional income equity. For example, the relative contribution of between-region inequality to the total increased by 0.70 percentage points with a slight increase of 0.002 in the Gini index for total income, as shown in Table 6. Further time series analysis will be required to identity whether such causality between subsidies and income distribution is stable.

\section{CONCLUSIONS AND POLICY IMPLICATIONS}

This paper analyzed sources of income inequality in Korea with respect to income source and region. This decomposition of the inequality index offers greater insight into the actual determinants of income inequality and the interlinkages between regions and income groups. Also, these indices showing overall income inequality within and between regions could serve as performance measures when assessing the regional and national policies aimed at balancing regional development. When the Gini index of overall income inequality was decomposed by geographical boundaries, the relative contribution of between-region inequality to the total inequality was 67.96 percent (a Gini index of 0.315) in 1995. Half of this income inequality (a Gini index of 0.234) was attributable to the difference in incomes between the Seoul Metropolitan Area and the rest of the nation; two-thirds of the degree of income inequality within regions (a Gini index of 0.101) was attributable to the income inequality between subregions in the Seoul Metropolitan Area. Given these data, any public policy needs to place an emphasis on the evolution of income distribution within the Seoul Metropolitan Area.

A few points should be mentioned for further research and development of a policy agenda. First, of the various income sources, wages and salaries were the most equally distributed across all income and regional groups, and this level of contribution was much lower than that of asset 
income by at least 18.3 percent. This highlights the point that the redistribution of asset and business income could be more effective in achieving regional planning goals than provision of opportunities for employment and investment outside the Seoul Metropolitan Area. In addition, government intervention reduces this inequality but also appears to intensify the differences between regions. Although subsidy income clearly had a positive impact as it improved the income distribution in terms of the Gini coefficient, at the same time it had an undesirable effect on regional inequality because the spatial characteristics were not taken into account when selecting a beneficiary for income subsidies. In order to reduce both income and regional inequalities, decision makers can set up a two-tier system: they first have a spatial allocation of income subsidies between regions and then identify the beneficiaries within each region.

\section{REFERENCES}

Atkinson, B., L. Rainwater, and T.M. Smeeding, 1995. Income Distribution in OECD Countries. OECD: Paris.

Adams, R.H., Jr., 1999. Non-Farm Income, Inequality, and Land in Rural Egypt. World Bank: Washington, D.C.

Adams, R.H., Jr., and H. Alderman, 1992. Source of Income Inequality in Rural Pakistan: A Decomposition Analysis. World Bank Policy Research Working Paper 836: Washington, D.C.

Azzoni, C.R., 2001. " "Economic Growth and Regional Income Inequality in Brazil," Annals of Regional Science 35(1), 133-152.

Bourguignon, F., 1979. "Decomposable Income Inequality Measures," Econometrica 47, 901920.

Byun, B., 1997. "The Dynamics of Regional Product Inequality by Expanded Rank-Size Functions," Ph.D. dissertation, University of Pennsylvania.

Choo, H., 1979. Income Distribution and Its Determinants in Korea. Korea Development Institute: Seoul, Korea.

Costa, M. and C. Michelini, 1999. "An Analysis of the Distribution of Income and Wealth Among Italian Households," Discussion Paper No. 99-11, Massey University: Turitea, New Zealand.

Daewoo Economic Research Institute, 1996. Korean Household Panel Study. Daewoo Economic Research Institute: Seoul, Korea.

Dagum, C., 1997. “A New Decomposition of the Gini Income Inequality Ratio," Empirical Economics 22, 515-531.

Foster, J., J. Greer, and E. Thorbecke, 1984. "A Class of Decomposable Poverty Measures," Econometrica 52, 761-766. 
Fujita, M., and D. Hu., 2001. "Regional Disparity in China, 1985-1994: The Effects of Globalization and Economic Liberalization," Annals of Regional Science 35(1), 3-37.

Glewwe, P., M. Gragnolati, and H. Zaman, 2000. Who Gained from Vietnam's Boom in the 1990s? An Analysis of Poverty and Inequality Trends. World Bank Policy Research Working Paper 2275: Washington, D.C.

Hong, S.W., 1990. “Regionalism and Regional Policy,” Journal of the Korean Regional Science Association 6(1), 1-10.

Hur, J., 1989. " "The Dynamic Pattern of Religion Inequalities and Testing of Hypothesis," The Journal of Korea Planners Association 24(2), 69-77.

Hwang, M.C., 1982. " "Regional Income Disparity and Regional Policies in Korea," The Korea Spatial Planning Review 1, 1-21.

Hyun, J., and S. Kang, 1998. "International Comparison of Korea's Income Distribution," Korean Economic Review 46(3), 145-167.

Jeong, J., and K. Choi, 2001. "The Decomposition Analysis of Factors of Household Income Inequality of Laborer," Korean Economic Review 49(3), 39-65.

Johnston, R., M. McKinney, and T. Stark, 1996. "Regional Price Level Variation and Real Household Incomes in the United Kingdom, 1979/80-1993," Regional Studies 30(6), 567588 .

Kim, E., S.W. Hong, and S.J. Ha, 2003. "Impacts of National Development and Decentralization Policies on Regional Income Disparity in Korea," The Annals of Regional Science 37(1): 79-91.

Kwon, S.W., I. Ko, K. Kim, and S. Kim, 1992. The State of Distribution Disparity and the Major Policy Issues in Korea. Korea Development Institute: Seoul, Korea.

Lee, J., 1997. A Theory of Income Distribution. Bibong Press: Seoul, Korea.

Mera, K., 1973. " "On the Urban Agglomeration and Economic Efficiency," Economic Development and Cultural Change 21, 309-324.

Milanovic, B., 1999. True World Income Distribution, 1988 and 1993: First Calculation Based on Household Surveys Alone. World Bank Policy Research Working Paper 2244: Washington, D.C.

Milanovic, B., and S. Yitzhaki, 2001. Decomposing World Income Distribution: Does the World Have a Middle Class? World Bank Policy Research Working Paper 2562: Washington, D.C.

Rao, D.C., 1978. "Economic Growth and Equity in The Republic of Korea," World Development 6(3), 383-396. 
Rho, E., and J. Bae, 1998. The Analysis of Regional Income Distribution and the Conditions of Life. Korea National Statistical Office: Seoul, Korea.

Silber, J., 1989. "Factor Components, Population Subgroups and the Computation of the Gini Index of Inequality," The Review of Economics and Statistics 71, 107-115.

Shorrocks, A., 1982. "The Impact of Income Components on the Distribution of Family Incomes," Quarterly Journal of Economics 98, 311-326.

Shorrocks, A., 1984. "Inequality Decomposition by Population Subgroup," Econometrica 52, 1269-1285.

Terrasi, M., 1999. "Convergence and Divergence Across Italian Regions," Annals of Regional Science 33(4), 491-510.

University of Michigan, 2003. Available at: http://www.isr.umich.edu/src/psid/.

Yemtsov, R., 2001. Inequality and Income Distribution in Georgia. World Bank Discussion Paper 252: Washington, D.C.

Yoo, S.Y., 1991. "Dynamic Changes of Regional Structure with Special Reference to Infrastructure Using a Multivariate Approach: The Case of Korea.” Ph.D. dissertation, University of Pennsylvania.

Zandvakili, S., and J.A. Mills. 2001. "The Distributional Implications of Tax and Transfer Programs in the U.S.," The Quarterly Review of Economics and Finance 41(2), 167-181. 